\title{
DIRECTIONAL SENSITIVITY OF ECHOLOCATION SYSTEM IN BATS PRODUCING FREQUENCY-MODULATED SIGNALS
}

\author{
By T. SHIMOZAWA *, N. SUGA, P. HENDLER AND S. SCHUETZE \\ Department of Biology, Washington University, St Louis, Mo. 63130, U.S.A.
}

(Received 12 fune 1973)

\section{INTRODUCTION}

For echolocation, bats emit sound and listen to echoes (Griffin, 1958). To investigate the directional sensitivity of their echolocation system it is necessary to measure the directional properties of both the orientation sounds and the ears. The field of the orientation sound around the head has been measured in Eptesicus and Chilonycterist (Simmons, 1969), Rhinolophus (Schnitzler, 1968) and Megaderma (Möhres, 1966). In these measurements the animal with its head unrestrained emitted sounds toward a target. Thus these data might include the effect of head movement. Sokorov \& Makarov (197I) fixed the head of Rhinolophus and measured the sound field produced by it. Recently, it has been found that sounds very similar to species-specific orientation sounds are elicited by electrical stimulation of the dorsal part of the reticular formation in the midbrain and/or the central grey matter of an unanaesthetized bat. In this case the head was immobilized by cementing it to a nail (Suga \& Schlegel, 1972). This technique makes possible accurate measurements of the sound fields produced by bats.

For sound localization at least two types of cues are conceivable: interaural pressure and time (or phase) differences. In man the interaural pressure difference (IPD) is used mainly for location of high-frequency sound, while the interaural time difference (ITD) is used mainly for low-frequency sound (Mills, I958, 1960; Stevens \& Newman, 1936). Since the bats of the genus Myotis are small and their orientation sounds are higher than $10 \mathrm{kHz}$, the IPD may be a primary cue for echolocation. The IPD as a function of azimuth is obtained from the directional sensitivity curve of the auditory system, which can easily be measured by recording summated or single neural activity (Grinnell, I963; Grinnell \& Grinnell, I965; Neuweiler, 1970; Suga, 1964).

To investigate the directional sensitivity of the echolocation system and the IPD as a function of azimuth, we therefore measured the sound fields produced by bats, and also the directional sensitivity of the auditory system in terms of summated neural activity.

Orientation sounds of Myotis are frequency-modulated (FM) so that an ITD can be coded by a group of neurones with different best frequencies on both the left and right sides. Possible roles of the ITD as well as the IPD are also discussed in relation to echolocation.

- Present address: Division of Biology, California Institute of Technology, Pasadena, Calif. gr 1og, U.S.A.

This bat is now called Pteronotus by Smith (1972). 


\section{MATERIALS AND METHODS}

Three grey bats (Myotis grisescens) and five little brown bats (M. lucifugus) were used. These two species are closely related, and there were no noticeable differences in orientation sounds and audiograms. Under ether anaesthesia a nail $1.5 \mathrm{~cm}$ long was mounted on the skull with acrylic adhesive and dental cement. Then the pinnae were carefully relocated to their original position by tightening the skin with sutures. A few hours to a day later the animal (now recovered) was placed on a $7.5 \mathrm{~cm}$ diameter vinyl ball floating on water. The head of the animal was fixed by fastening the nail to a metal rod with a set screw. The midpoint of the ears was placed at the centre of the acoustic perimeter and the eye-nostril line was made horizontal. The nail, the rod supporting it, and the floating ball were at least $20^{\circ}$ posterior to the animal's mouth.

Without anaesthesia, a small hole was made in the skull through which a double steel electrode with a few megohms resistance was inserted for the electrical stimulation of the midbrain to elicit FM sounds similar to species-specific orientation signals (Suga \& Schlegel, 1972). After fixing the electrode in place with dental cement, the micromanipulator used for positioning it was removed. The electrical stimulus applied to the brain was a short train of pulses delivered twice per second. Each train consisted of Io electric pulses, each having a duration of $0.1 \mathrm{msec}$ and an amplitude of $1-15 \mathrm{~V}$. The inter-pulse interval was $\mathrm{I} \cdot 7 \mathrm{msec}$.

The sounds elicited by the bat were recorded with two quarter-inch condenser microphones (Brüel \& Kjaer 4I35). One, 'reference microphone' pointed toward the bat's mouth and was positioned $5^{\circ}$ right, $5^{\circ}$ down from the eye-nostril line, and $70 \mathrm{~cm}$ anterior to the mouth. The other, 'the scanning' microphone, mounted on a movable aluminium arm in order to scan the bat's perimeter at a $50 \mathrm{~cm}$ radius, was also aimed at the mouth. Since the sounds emitted by the bat were frequency-modulated, the interference between the signal directly incident upon the microphones and the echoes was easily detected, because the overlap of the delayed echoes with the signal produced ripples in the envelope of the recorded signal. To minimize these echoes, objects in the sound-proofed room were covered with cotton. An Ampex FR-Ioo tape recorder (frequency response: $300-300000 \mathrm{~Hz}$ at $60 \mathrm{in} / \mathrm{sec}$ ) simultaneously recorded the following signals: electrical stimuli applied to the brain, bat's sound monitored with the reference and scanning microphones, and electric signals indicating the position of the scanning microphone. At each position of the scanning microphone about I5 FM sounds emitted by the bat were recorded.

The recorded signals were played back at $\frac{1}{32}$ of the original tape speed. A 2 sec square pulse triggered by the electrical stimulus controlled the shutter of a camera, while the pulse synchronized with the onset of the bat's sound triggered the sweep of a cathode-ray oscilloscope. The sound monitored with the reference microphone was fed into the period meter in order to examine the frequency sweep. The output of the period meter and the tape-recorded sounds were simultaneously displayed on the oscilloscope screen and were photographed. A $3125 \mathrm{~Hz}$ signal, which corresponds to $100 \mathrm{kHz}$ at the original tape speed was also fed into the period meter prior to the tape-recorded sound and its output was also displayed for purposes of calibration (Fig. $x$ ). In addition, the signal indicating the location of the scanning microphone was 


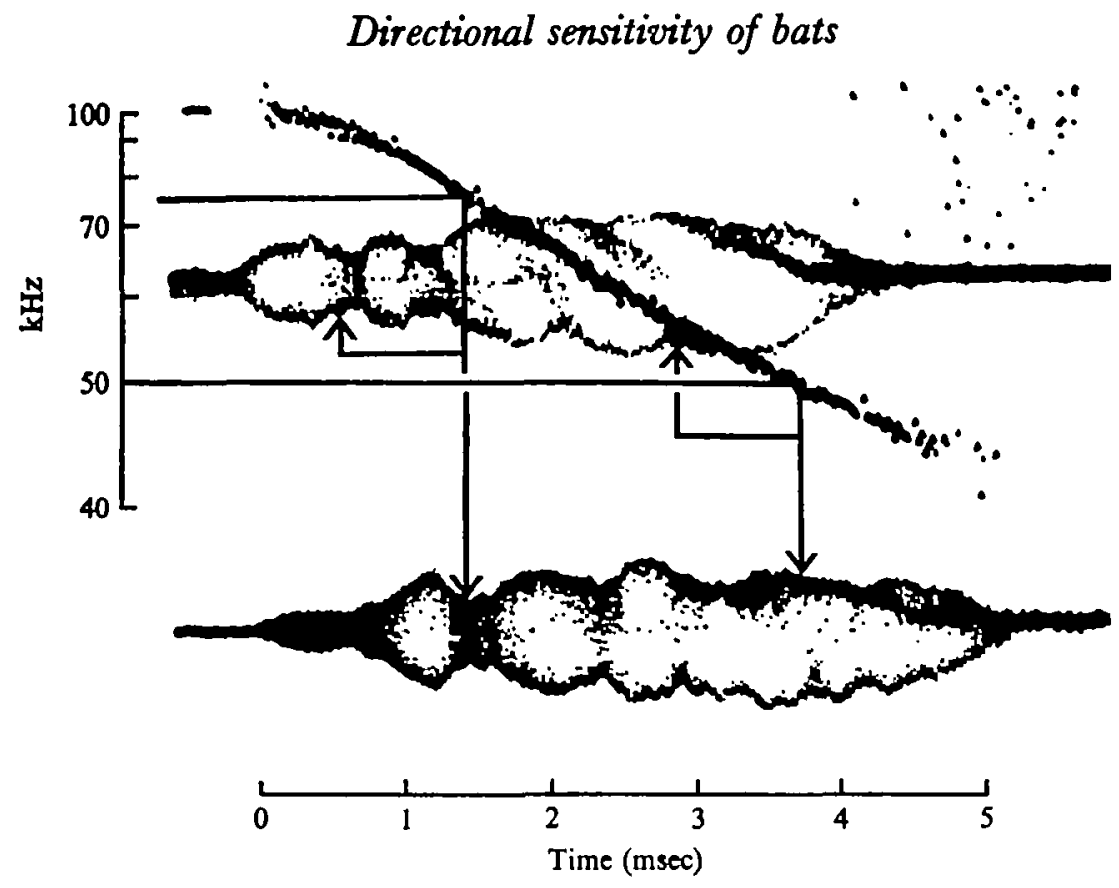

Fig. I. A photograph used for amplitude measurement of an FM sound emitted by M. grisescens. The sound waves monitored with the scanning and reference microphones are shown in the upper and lower traces, reopectively. The period meter output is simultaneously displayed by dots with a short calibration aignal of $100 \mathrm{kHz}$ on the left. The arrows indicate the corresponding amplitude of either the 50 or $75 \mathrm{kHz}$ component. The frequency scale for the period meter output is given to the left in kilo-Hertz, and the time scale at the bottom in milliseconds.

displayed on an oscilloscope screen. In Fig. I the frequency of a bat's sound sweeps from $100-43 \mathrm{kHz}$. Since there were no noticeable harmonics for the components higher than $50 \mathrm{kHz}$, the radiation patterns of sounds higher than $50 \mathrm{kHz}$ could be studied by measuring the peak-to-peak amplitudes. In our experiments the amplitude of the 55,75 , and $95 \mathrm{kHz}$ components were measured in FM sounds monitored with the reference and scanning microphones, and the difference in amplitude at the two microphones was expressed in either percentage of, or decibels below, maximum. Assuming sagittal symmetry, each point in our data represents the average of six measurements.

To study the relationship between mouth movement and sound emission a photoelectric displacement transducer was connected to the lower jaw of one animal by a rubber band, and a quarter-inch microphone was placed $10 \mathrm{~cm}$ anterior to the bat. The outputs of the transducer and microphone were simultaneously displayed on an oscilloscope screen (Fig. 2).

For the measurement of the directional sensitivity of the auditory system a tungsten electrode was inserted into the nucleus of the lateral lemniscus to record its activity evoked by acoustic stimuli. This is hereafter called the $L L$ response (equivalent to $N_{4}$ ). The $L L$ response was selected, because it is more directional than the summated neural activity of primary auditory neurones $\left(N_{1}\right)$ as a result of binaural interaction occurring in medullary auditory nuclei (Grinnell, 1963). Instruments for acoustic stimulation and recording were the same as those described in the previous paper (Suga, 197I). A condenser loudspeaker was moved around the head in the horizontal 
(a)

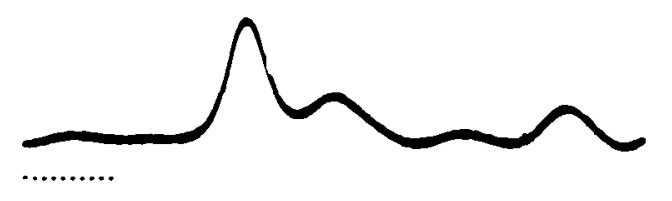

(b)

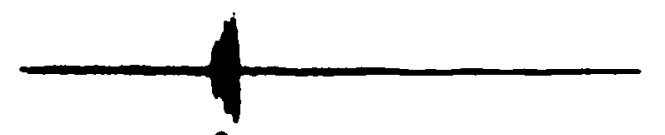

(c)
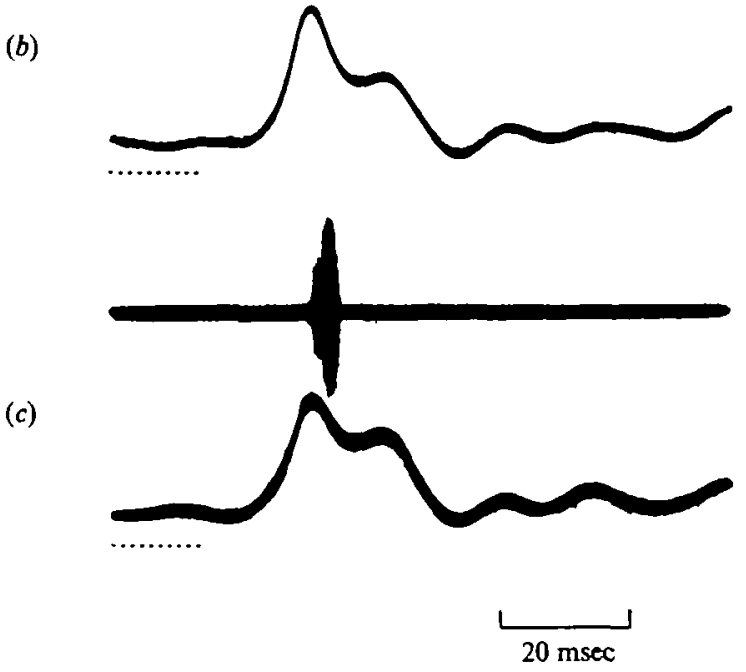

Fig. 2. Relationship between the sound emission (upper trace) and mouth movement in $M$. grisescens (lower trace). The upward deflexion of the lower trace represents the mouth opening. Sounds are emitted around the maximum opening of the mouth. Dots on the left represent the electrical stimuli applied to the midbrain. All three pictures were obtained from one bat under the same stimulus conditions. The time scale is $20 \mathrm{msec}$.

plane at $66 \mathrm{~cm}$ radius, and thresholds of $L L$ responses to $35,55,75$, and $95 \mathrm{kHz}$ sounds were measured as a function of azimuth. These acoustic stimuli had a rise-decay time of $0.2 \mathrm{msec}$ and a duration of $4 \mathrm{msec}$.

\section{RESULTS}

Sound fields produced by bats. When an electrical stimulus was applied to the dorsal part of the reticular formation in the midbrain, the bat opened its mouth $50-60^{\circ}$ and emitted an FM sound with a latency of $30-50 \mathrm{msec}$. This was very similar to the species-specific orientation sound used in the searching phase of echolocation. The amplitude of the emitted sound ranged from 100-1 Io dB SPL (sound pressure level referred to 0.0002 dyne $/ \mathrm{cm}^{2}$ r.m.s.) at $10 \mathrm{~cm}$ in front of the mouth. Its duration was between 3 and $5 \mathrm{msec}$. The frequency always swept downward from Ioo-ca. $45 \mathrm{kHz}$. If such an FM sound was emitted at different phases of mouth movement, the sound field measured would show large variations; the relationship between the sound emission and mouth movement was thus first studied. As shown in Fig. 2, the sound emission was not strictly locked to a certain phase of the mouth movement, but iv 
A

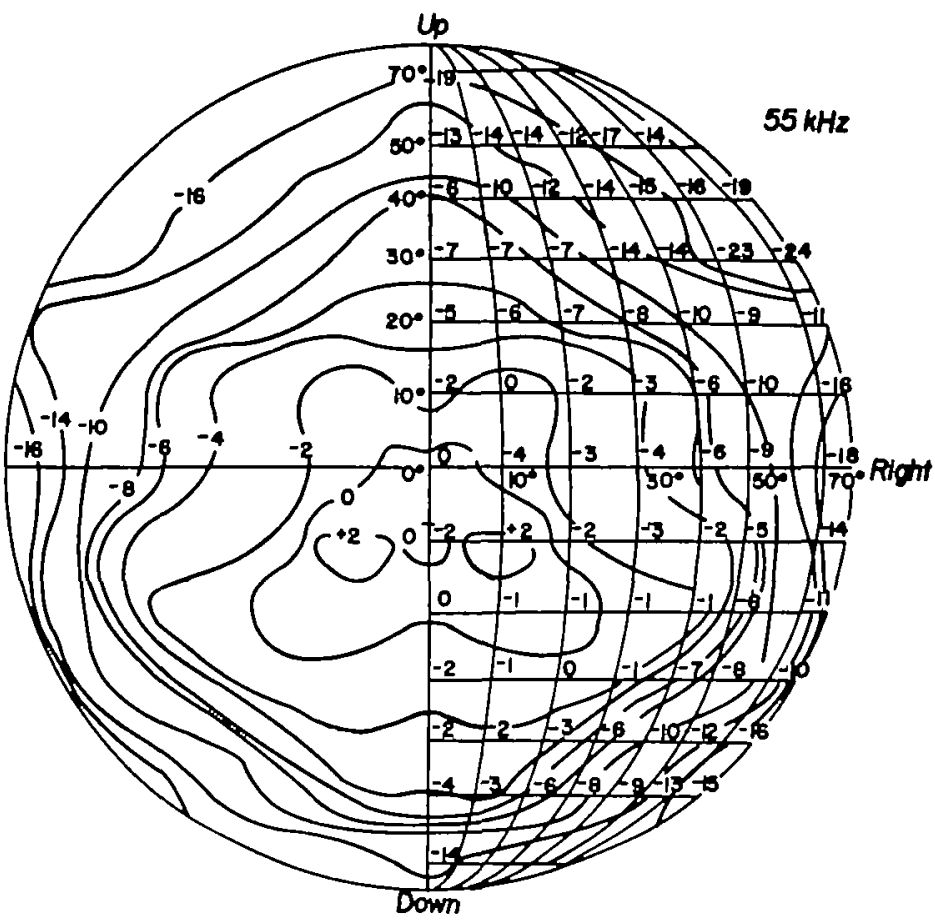

B

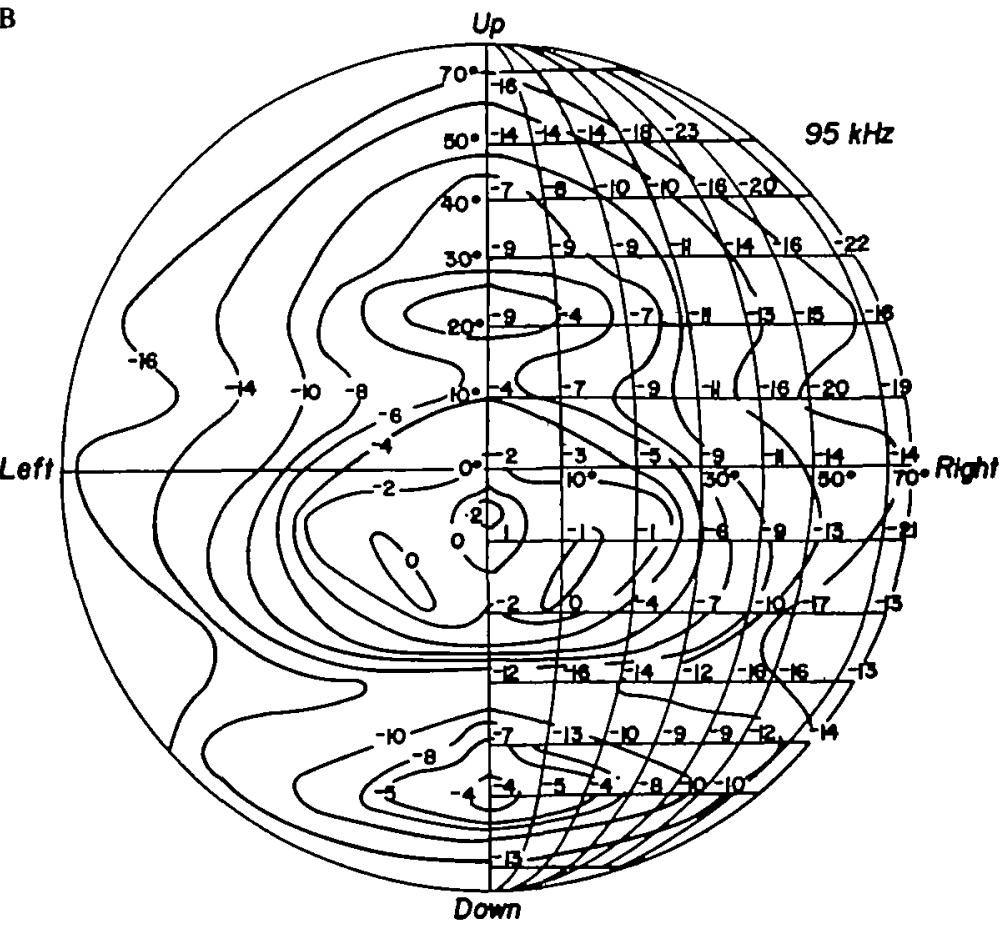

Fig. 3. Radiation patterns of the 55 and $95 \mathrm{kHz}$ components in FM sounds produced by $\boldsymbol{M}$. grisescens. Each number near the ordinate crosspoints represents a sound pressure relative to that at the reference point $\left(5^{\circ}\right.$ right and $5^{\circ}$ down) in decibels. The contours were drawn by interpolation through theac values. Zero degree is defined as the eye-nostril line. A, $55 \mathrm{kHz}$; B, $95 \mathrm{kHz}$. 


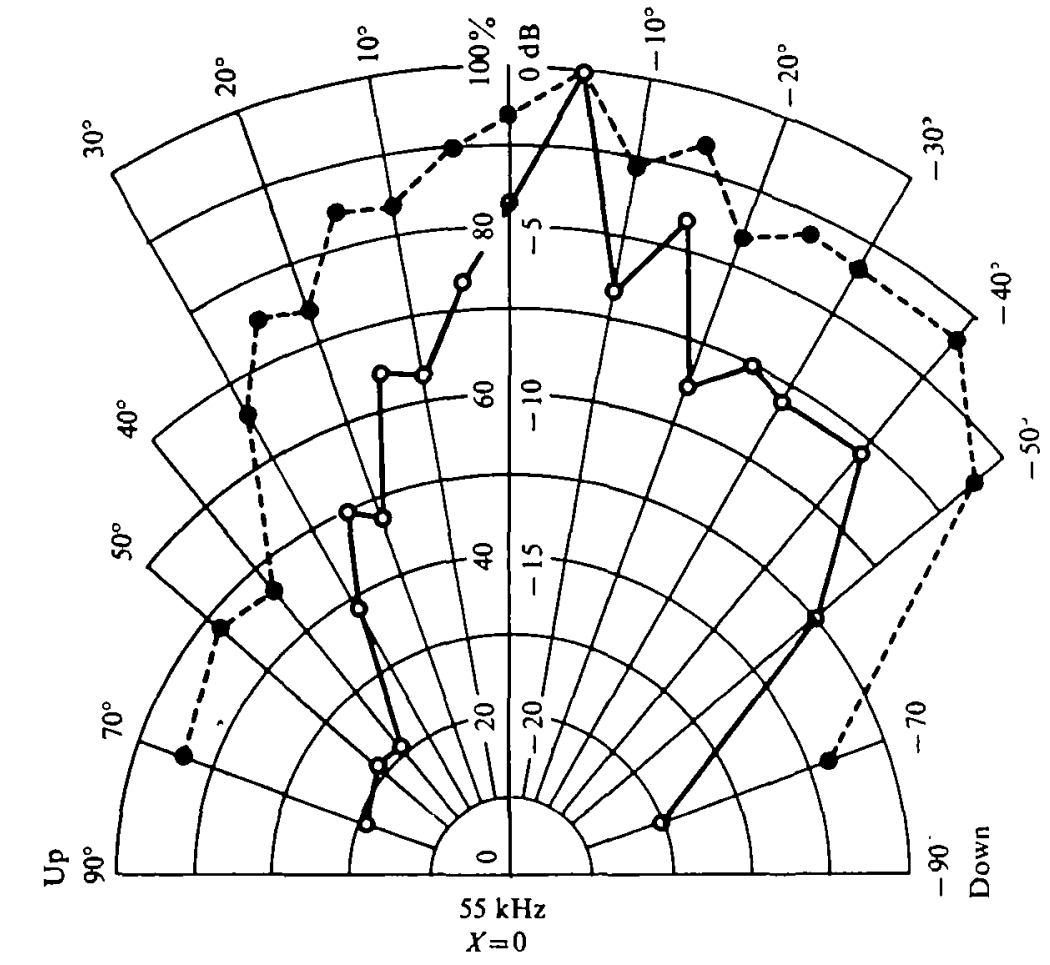

5

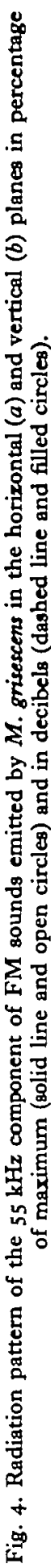




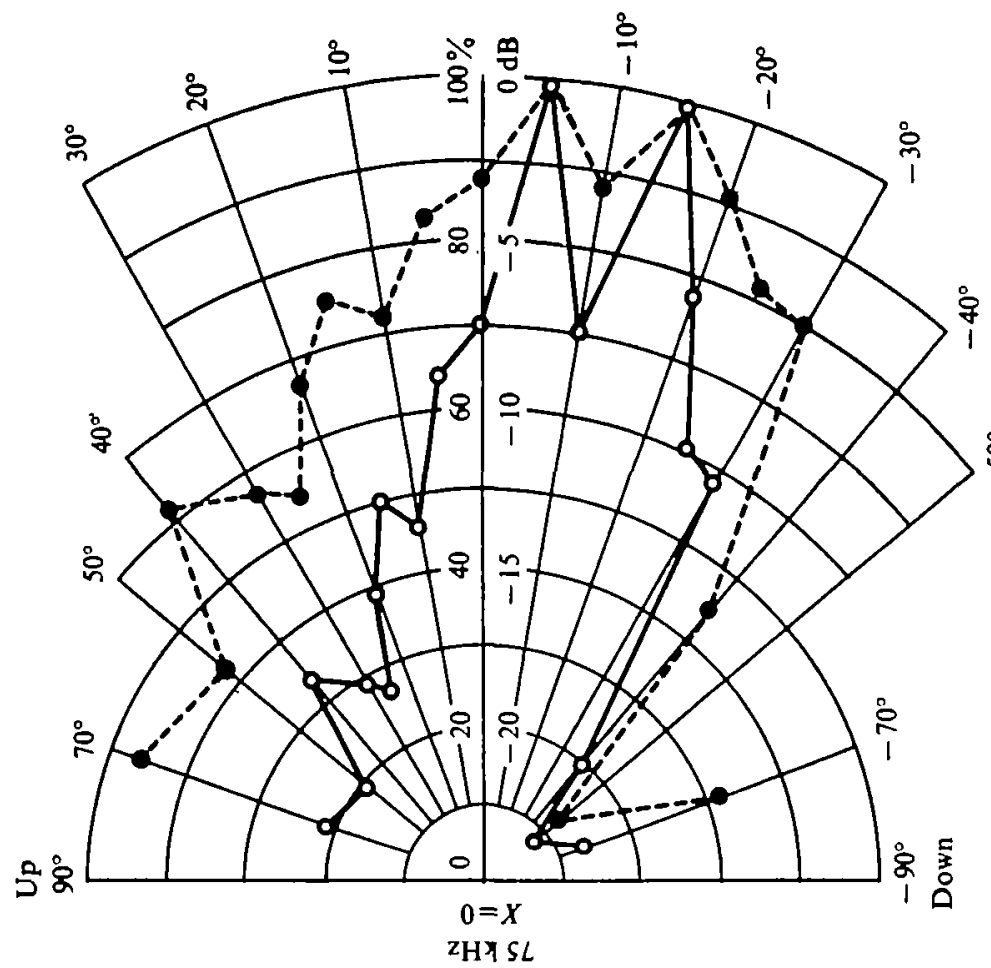

3

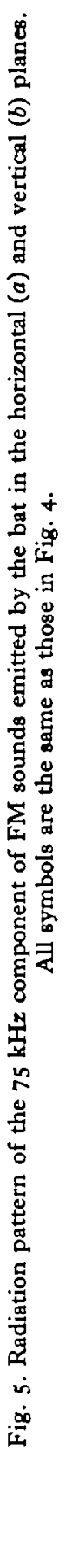




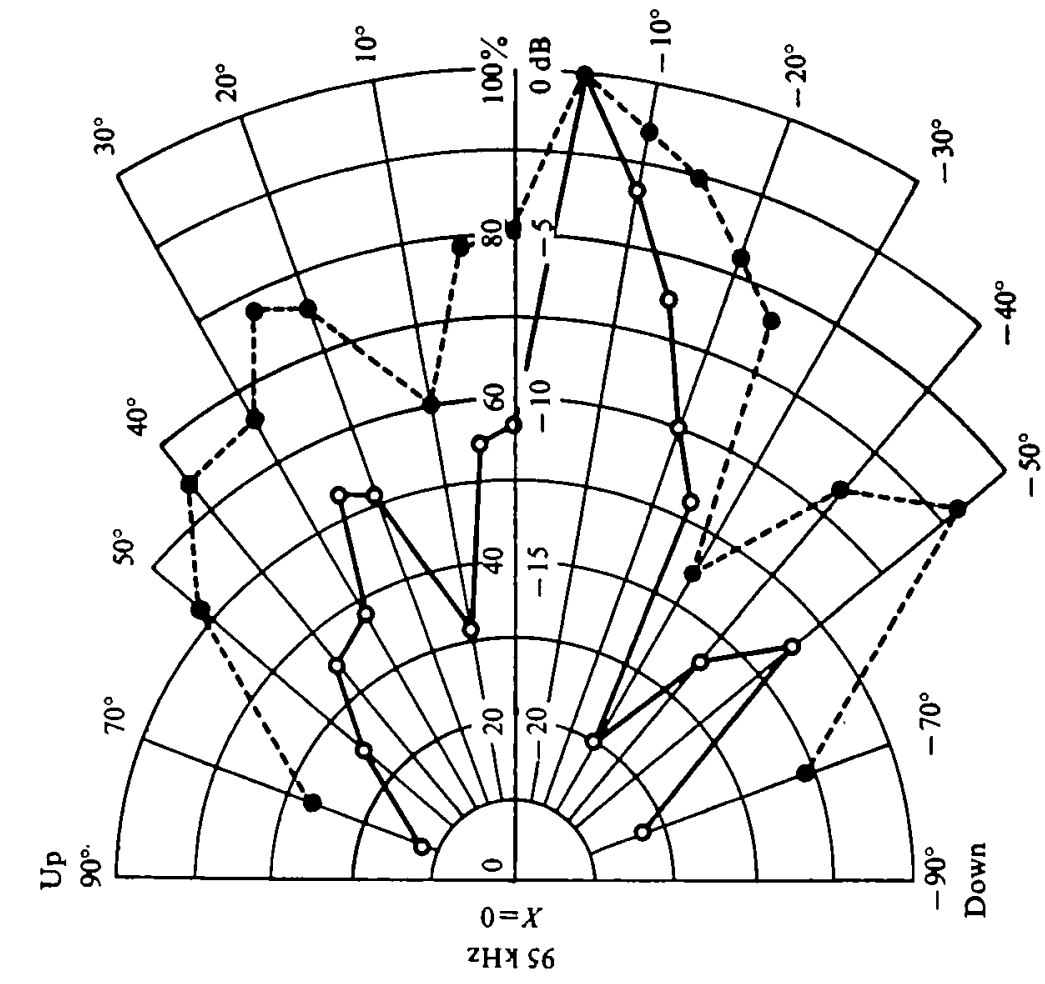

0

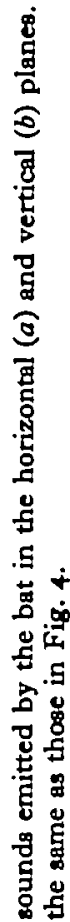

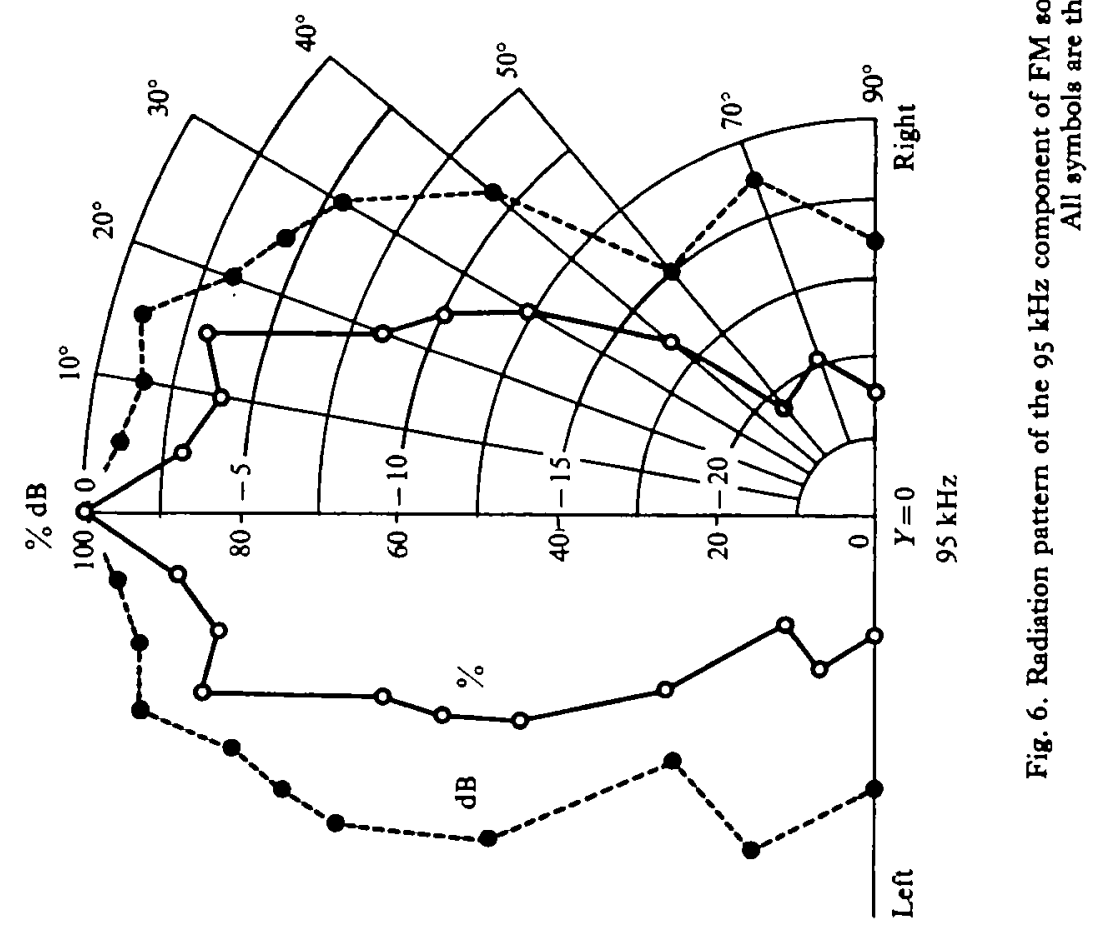




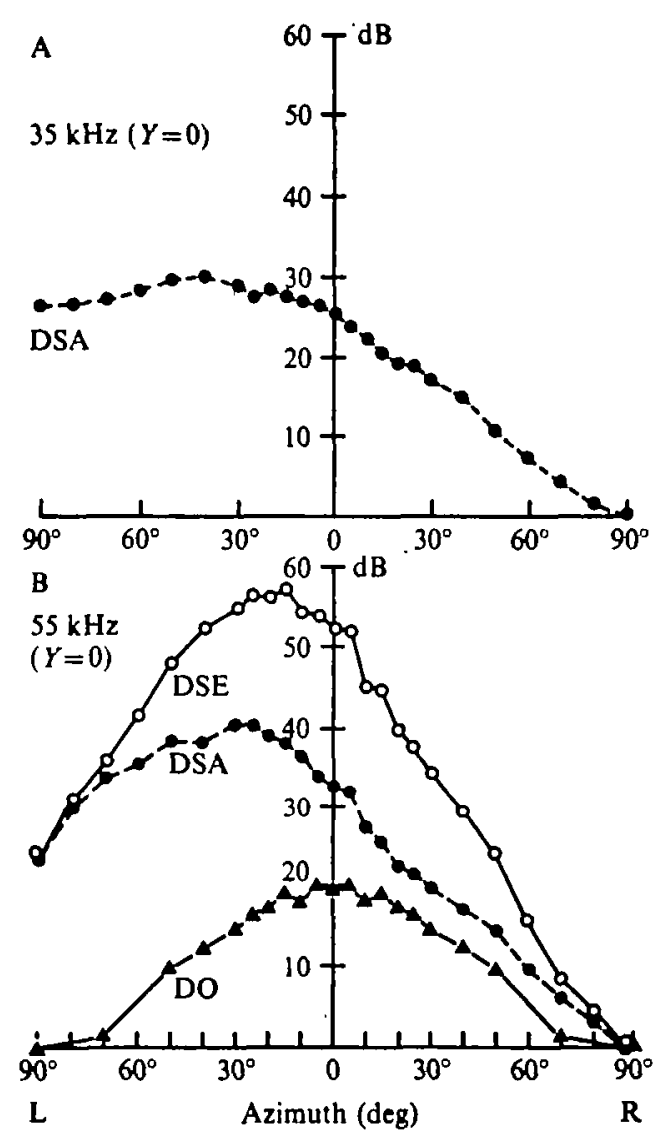

Fig. 7

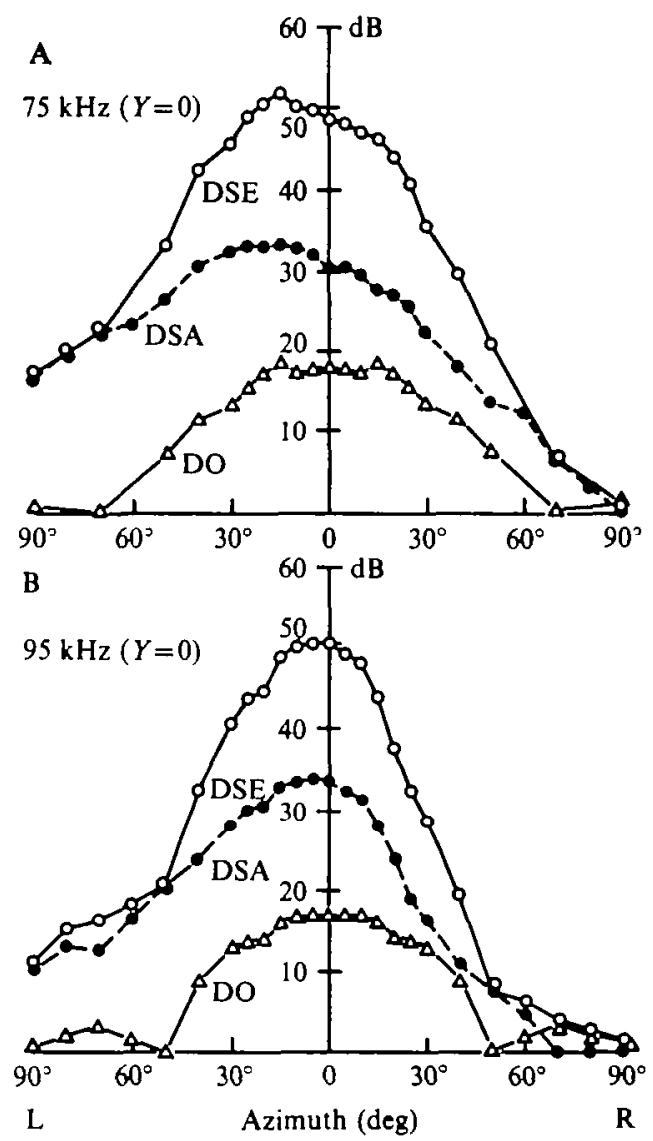

Fig. 8

Fig. 7. (A) the directional sensitivity of the auditory system (DSA) at $35 \mathrm{kHz}$. (B) DSA, directionality of the orientation sound (DO) and directional sensitivity of the echolocation system (DSE) at $55 \mathrm{kHz}$. Each DSA curve is the average of measurements with 5 bats, while each DO curve is the average of data obtained from 2 bats. The ordinates and abscissae represent sensitivity in decibels and azimuth in degrees, respectively.

Fig. 8. The DSA, DO and DSE at 75 (A) and $95 \mathrm{kHz}(B)$. Each DSA curve is the average of measurements with 5 bats, while each DO curve is the average of data obtained from 2 bats. All symbols are the same as those in Fig. 7.

occurred anywhere between slightly earlier and slightly later than the peak opening of the mouth, so that a given component of the FM sound might be emitted at any aperture of the mouth between $30-60^{\circ}$. Thus, the sound field varied for each sound. This variation was within $\pm 12 \%$ of the mean amplitude.

Fig. 3 shows an example of sound fields produced by $M$. grisescens ( $\mathrm{Mg} \mathrm{I})$. The contour map shows that the sound is strongly radiated in a direction of $5-10^{\circ}$ downward from the eye-nostril line and the main lobe is sharper at higher frequencies. Figs. 4-6 show radiation patterns of the 55,75 , and $95 \mathrm{kHz}$ components, respectively, in the horizontal and vertical planes produced by $\mathrm{Mg} \mathrm{I}$. All directional patterns were normalized with respect to the maximum amplitude for each component. The radiaton angle at half-amplitude of maximum was $38^{\circ}$ lateral, $18^{\circ}$ up and $50^{\circ}$ down at 
$55 \mathrm{kHz}, 34^{\circ}$ lateral, $8^{\circ}$ up and $32^{\circ}$ down at $75 \mathrm{kHz}$, and $30^{\circ}$ lateral, $5^{\circ}$ up and 2 down at $95 \mathrm{kHz}$ (Figs. 4-6). Thus, the width of the main lobe becomes narrower with an increase in frequency. At $95 \mathrm{kHz}$ two prominent side lobes were present: one oriented $25^{\circ}$ upward and the other $50^{\circ}$ downward (Fig. 6). Two other bats showed different values, which were broader in angle at half-amplitude than $\mathrm{Mg}$ I.

Since the measurement of sound pressure was performed in $5^{\circ}$ or $10^{\circ}$ steps, there was a possibility that sharp lobes which might exist for high frequencies were missed. The fields of 55,75 and $95 \mathrm{kHz}$ sounds were therefore measured around a loudspeaker with an aperture comparable to that of the bat's mouth. This measurement indicated that the presence of such lobes in addition to those in Fig. 4 was unlikely. The main lobe calculated by Strother \& Mogus (1970) is also compatible with our data. Furthermore, there was a possibility that the ball under the bat modified the sound field in the hemisphere in front of the bat. The sound field around the loudspeaker was also measured with and without the ball. The result demonstrated that the sound field in front of the bat was not noticeably different.

Directional sensitivity of the auditory system $(D S A)$. When a tungsten-wire electrode was inserted into the lateral lemniscus, the $L L$ response (lateral lemniscal evoked potential) to a tonal stimulus was $\mathrm{I}-2 \mathrm{mV}$ in amplitude. The loudspeaker was then moved in the horizontal plane including the eye-nostril line, and the threshold of the $L L$ response to the sound was measured as a function of azimuth angle. The DSA was expressed by the reciprocal of the threshold. Figs. 7, 8 show DSA curves measured with either 35 and $55 \mathrm{kHz}$ or 75 and $95 \mathrm{kHz}$ tones. Each curve is the average of measurements with 5 different bats. The $L L$ response was most sensitive to sounds delivered from the contralateral side, so that impulses for the lateral lemniscus mainly originated from the contralateral ear. The maximum sensitivity appeared at $38 \pm 7.5^{\circ}$ azimuth to the midline for $35 \mathrm{kHz}, 27 \pm 9.0^{\circ}$ for $55 \mathrm{kHz}, 18 \pm 7.5^{\circ}$ for $75 \mathrm{kHz}$ and $5.0 \pm 8 \cdot \mathrm{I}^{\circ}$ for $95 \mathrm{kHz}$. The slope of the DSA curve toward and beyond the midline was $0.28 \pm 0.03,0.43 \pm 0.03,0.42 \pm 0.03$ and $0.58 \pm 0.03 \mathrm{~dB} /$ degree for $35,55,75$, and $95 \mathrm{kHz}$, respectively. Since higher-frequency sounds were more directional, it was expected that the slope of the DSA curve would increase with frequency, but it was not anticipated that the maximally sensitive direction would move medially with increasing frequency.

Directional sensitivity of the echolocation system (DSE). The DSE was obtained by adding the two curves for the directionality of the orientation sound (DO) and the DSA. As shown in Figs. 7, 8, the slopes of the DSE curve on both sides of its peak are about $0.6 \mathrm{~dB} /$ degree at $55 \mathrm{kHz}, 0.8 \mathrm{~dB} /$ degree at $75 \mathrm{kHz}$, and $\mathrm{I} \cdot 0 \mathrm{~dB} /$ degree at $95 \mathrm{kHz}$. These results confirm that the DSE increases in sharpness with frequency. The peak of the DSE curve is $15^{\circ}$ lateral for $55 \mathrm{kHz}, 15^{\circ}$ lateral for $75 \mathrm{kHz}$, and $2.5^{\circ}$ lateral for $95 \mathrm{kHz}$. It was noticed that the peak for a $95 \mathrm{kHz}$ sound was very close to the midline.

Interaural pressure difference (IPD). Since the IPD appeared to be the essential cue for echolocation in bats of the genus Myotis, it was calculated as a function of azimuth angle for $35,55,75$, and $95 \mathrm{kHz}$. We assumed sagittal symmetry of the auditory system. The DSA or DSE curves in Figs. 7,8 were inverted at zero degrees. The IPD curves in Fig. 9 were then obtained by subtracting the inverted curves from the non-inverted ones. The IPD for a $35 \mathrm{kHz}$ sound changed linearly with 


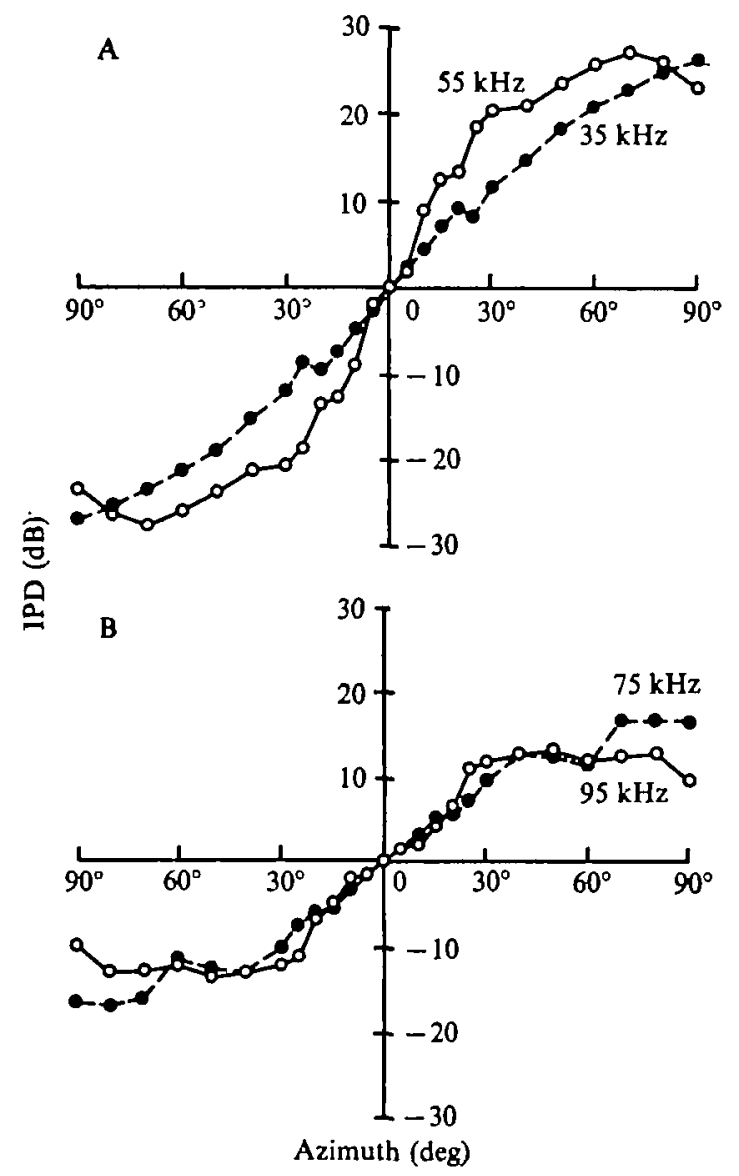

Fig. 9. Interaural pressure differences (IPD) as a function of azimuth at either 35 and $55 \mathrm{kHz}_{z}$ (A) or 75 and $95 \mathrm{kHz}$ (B). The ordinates and abscissae represent the IPD in decibels and azimuth in degrees, respectively. These curves were obtained from the data presented in Figs. 7,8 .

azimuth between $0-50^{\circ}$ at a rate of $0.4 \mathrm{~dB} /$ degree. Beyond $60^{\circ}$ it changed at a rate of $0.2 \mathrm{~dB} /$ degree. For a $55 \mathrm{kHz}$ sound the slope of the IPD curve was $0.7 \mathrm{~dB} /$ degree between $0-30^{\circ}$ lateral, and $0.2 \mathrm{~dB} /$ degree beyond $30^{\circ}$. For 75 and $95 \mathrm{kHz}$ sounds the slope of the IPD curve was $0.3-0.4 \mathrm{~dB} /$ degree between $0^{\circ}$ and $30^{\circ}-40^{\circ}$ lateral, but it becomes nearly zero beyond $40^{\circ}$. These data indicate that a $55 \mathrm{kHz}$ sound gives a larger IPD cue than do 35,75 , and $95 \mathrm{kHz}$ sounds and that the IPD cue for sounds higher than $75 \mathrm{kHz}$ is very poor at positions more lateral than $30^{\circ}$.

\section{DISCUSSION}

Sound fields. Sound fields produced by different species of bats have been measured by Möhres (1966), Schnitzler (1968), Simmons (1969), and Sokolov \& Makarov (1971). Except for Sokolov \& Makarov's extensive study, the animals did not have a head-holding device when they emitted orientation sounds toward a target. The azimuth angle at half-amplitude of maximum is $23^{\circ}$ at $28-30 \mathrm{kHz}$ for Eptesicus fuscus 
and Pteronotus parnellii rubiginosus (previously called Chilonycteris rubiginosa) whic' emit sounds through the mouth (Simmons, 1969 ), and $2 \mathrm{I}-23^{\circ}$ at $83 \mathrm{kHz}$ for Rhinolophus ferrumequinum which emits signals through the nostrils (Möhres, I966; Schnitzler, I 968), and $35^{\circ}$ at $60-80 \mathrm{kHz}$ for Megaderma lyra (Möhres, I966). According to Sokolov \& Makarov (1971) who fixed the head of Rhinolophus, the azimuth angle at a half-amplitude is $28^{\circ}$, but it is $30^{\circ}$ after amputating the nose-leaf. Thus, the effect of the nose-leaf on horizontal radiation is very small. This is unexpected data for us, because we had the impression that Rhinolophus emitted an orientation sound in a narrower beam than that of Myotis and Eptesicus, since Rhinolophus emits a highfrequency sound through nostrils which are surrounded by the nose-leaf.

In our data on $\mathrm{Mg}$ I, the horizontal angle at a half of maximum amplitude is $34^{\circ}$ at $75 \mathrm{kHz}$ and $30^{\circ}$ at $95 \mathrm{kHz}$, which are comparable to the data obtained by Sokolov \& Makarov (1971). Conversely, the azimuth angle at half-amplitude at $55 \mathrm{kHz}$ in $\mathrm{Mg} \mathrm{I}$ $\left(38^{\circ}\right)$ is much wider than that at $28-30 \mathrm{kHz}$ in Eptesicus and Pteronotus (Simmons, 1969).

The vertical distribution of an orientation sound has been measured only with Rhinolophus. The vertical angular width at a half-amplitude of maximum at $83 \mathrm{kHz}$ is $43^{\circ}$ according to Schnitzler (1968) and $73^{\circ}$ according to Sokolov \& Makarov (1971). The large angular width obtained by Sokolov and Makarov is due to the fusion of the main and side lobes. Interestingly, the dissection of the nose-leaf greatly reduces the vertical width down to $46^{\circ}$ because of the reduction in the side lobes. Rhinolophus moves the nose-leaf during echolocation, probably to control the vertical distribution of orientation sounds. In our data with $\mathrm{Mg} \mathrm{I}$, the vertical angular width of the main lobe at half-amplitude was $68^{\circ}$ at $55 \mathrm{kHz}, 40^{\circ}$ at $75 \mathrm{kHz}$ and $30^{\circ}$ at $95 \mathrm{kHz}$.

Interaural pressure difference (IPD). Since the DSE curves showed sharp slopes $(0.6 \mathrm{~dB} /$ degree at $55 \mathrm{kHz}$ and $\mathrm{I} \cdot 0 \mathrm{~dB} /$ degree at $95 \mathrm{kHz})$, the amplitudes of echoes at the ears greatly decrease as echo sources move away from the maximally sensitive direction. Accordingly, clatter from irrelevant sources at the ears is greatly reduced. If the peaks of the DSA curves were more lateral than those in Figs. 7, 8, the IPD and the dynamic ranges of the IPD curves would increase, but the peaks of the DSE curves would decrease and move laterally. In other words, the IPD and the DSE are mutually dependent. For echolocation the peak of the DSA curve should be thus neither too lateral nor too medial. The dynamic ranges of the IPD curves greatly depend on the difference between the slopes of the DSA curves toward the ipsi- and contralateral sides. To increase the dynamic range, the slope lateral to the peak of the DSA (or DSE) curve should be smaller than that on the medial side. This was found true for lower frequencies but not for higher ones.

For comparison with the present data, a DSA curve (Neuweiler, 1970) and a directionality curve of orientation sound (Schnitzler, 1968) of Rhinolophus ferrumequinum are replotted in Fig. Io $A$. The frequency of sound used for these measurements was $83.3 \mathrm{kHz}$. The slope of the DSE curve is $0.5-0.6 \mathrm{~dB} /$ degree. The IPD varies linearly with azimuth angle from $0-30^{\circ}$ lateral at a rate of $0.5 \mathrm{~dB} /$ degree. It does not, however, change as the azimuth angle increases beyond $30^{\circ}$ (Fig. Io B). The IPD curve of Rhinolophus is thus similar to that of Myotis (whether the difference between the two curves in Fig. IOB is significant or not is subject to future experimentation). 

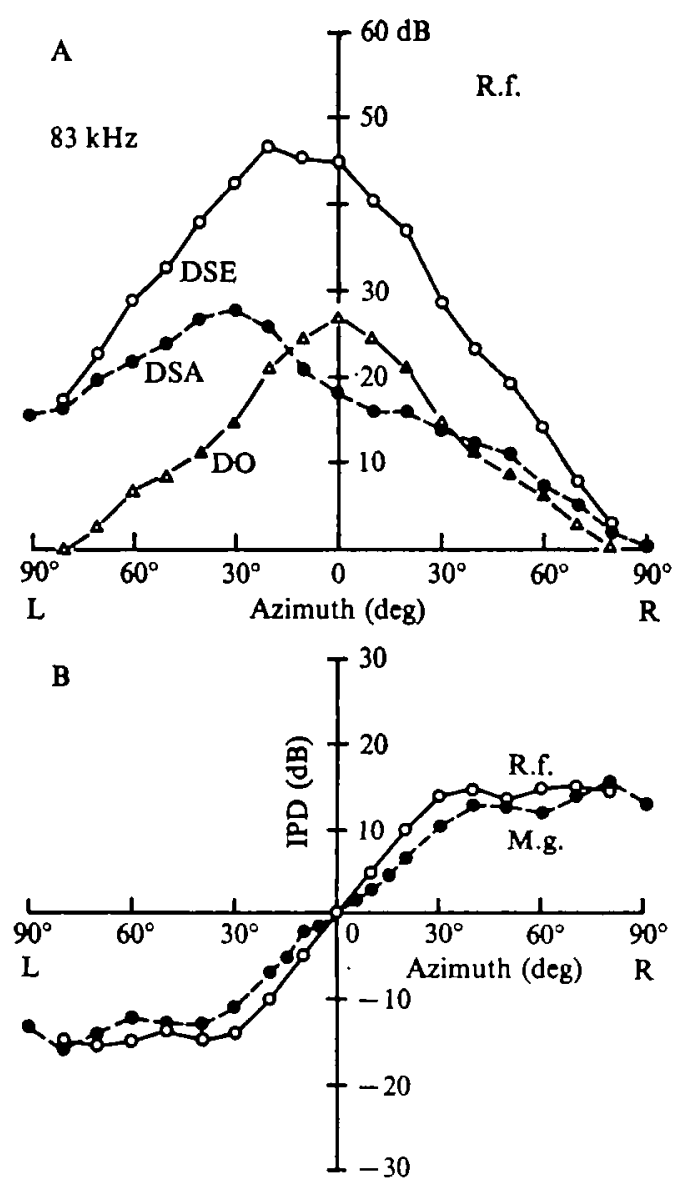

Fig. Io. DSA, DO, DSE and IPD of Rhinolophus (R.f.) as a function of azimuth at $83 \mathrm{kHz}$. For comparison, the IPD curve of Myotis (M.g.) is also shown, which is the average of the curves for 75 and $95 \mathrm{kHz}$ in Fig. 9. All symbols are the same as those in Figs. 7, 9.

Rhinolophus moves the pinnae synchronously with vocalization and does not change the frequency of CF-FM (constant-frequency plus frequency-modulated) sound more than a few $\mathrm{kHz}$ during echolocation (Schnitzler, I968), while Myotis does not move the pinnae during vocalization and greatly drops the frequency of FM sounds when hunting insects and when landing (Griffin, 1958). Thus, the dynamic range of the IPD curve may alternately shift left or right in Rhinolophus, while it broadens in Myotis.

Both the narrow dynamic range of the IPD curve for higher frequencies and the decrease in frequency of FM orientation sounds during the approach and terminal phases appear to be disadvantageous for echolocation and target characteristics. However, Myotis may have not only this disadvantage, but also some advantage. During a searching phase Myotis emits FM sounds sweeping from $100-45 \mathrm{kHz}$. At these frequencies, the slope of the DSE curve toward a lateral side is very sharp, so that any clatter which may be produced by irrelevant objects and/or other bats more lateral than $30^{\circ}$ is greatly attenuated. Since the distance to a target is long in the search phase, 
a wide dynamic range for echolocation may not be needed by the bats, so the narror dynamic range may not necessarily be disadvantageous for echolocation. The bats can efficiently find small objects in front of them with a sound of such a high-frequency, although higher-frequency sounds are attenuated by the air more than lower-frequency sounds. The target characteristics may be performed during and/or just before the approach phase. During the terminal phase and the latter part of the approach phase Myotis emits FM sounds sweeping down about one octave between $50-15 \mathrm{kHz}$ (e.g. from $40-20 \mathrm{kHz}$ ) at a high repetition rate. In these phases tracking of the target may be most important. Since the distance to the target is short, the direction of the target may quickly change, so that a wide dynamic range for echolocation and the frequent emission of orientation sounds may be more important to the bat.

In man the just-detectable IPD is $0.5 \mathrm{~dB}$ at $2-3 \mathrm{kHz}$ and $50 \mathrm{~dB}$ above the sensation level which corresponds to $\mathrm{a} \cdot \mathbf{2}-\mathbf{2} \cdot 5^{\circ}$ lateral shift of a sound source from the midline (Mills, 1960). In our data on Myotis the slope of the IPD curve around the midline was $0.4,0.7,0.3$, and $0.4 \mathrm{~dB} /$ degiee for $35,55,75$, and $95 \mathrm{kHz}$ sounds, respectively. If one assumes that the just-detectable IPD of Myotis is $0.5 \mathrm{~dB}$, the bat may be able to detect a $0 \cdot 7-r \cdot 7^{\circ}$ azimuth difference around the median plane. Harrison \& Downey (1970) measured the IPD with Phyllostomus hastatus and obtained the minimum detectable angular difference of $2 \cdot 0^{\circ}$ at $10 \mathrm{kHz}$ and $2 \cdot 3^{\circ}$ at $20 \mathrm{kHz}$. They assumed the just-detectable IPD to be $0.5 \mathrm{~dB}$. Behavioural experiments with bats indicate that Eptesicus fuscus with an interaural distance of $14 \mathrm{~mm}$ can detect a $6-8^{\circ}$ azimuth difference and $P$. hastatus with an interaural distance of $22 \mathrm{~mm}$ can detect a $4-6^{\circ}$ difference with their orientation sounds (Peff \& Simmons, 1971). These behavioural data can be explained by the IPD cue without assuming that the bat can detect a much smaller IPD than can man. There is no doubt that the IPD is the essential cue for echolocation. Since Myotis can catch two separate Drosophila within a half second (Griffin, Webster \& Micheal, I960), the minimum detectable azimuth difference in Myotis may be smaller than the behavioural values cited above.

Pumphrey (1948) stated that sound localization is accomplished by the binaural comparison of intensity ratios at least at three different frequencies to which the ear shows different polar diagrams of sensitivity. As a matter of fact, the polar diagrams of the ears of owls (Payne, 196I) and bats (Neuweiler, 1970; Grinnell \& Grinnell, I965) change extensively with the frequency of sound and also with the position of the external ear. This is also true in man (Sivian \& White, 1933), so that the spectrum density of a complex sound differs at the two ears (Nordland \& Fritzell, 1963). The source of a complex sound is thus more easily located than that of a pure tone. Thus, FM sounds are apparently better signals for echolocation than CF sounds.

Responses of auditory neurones vary not only in discharge pattern, but also in latency with stimulus amplitude. In Myotis the difference in latency between the left and right $L L$ responses to a tonal stimulus due to the IPD appears to be much larger than the ITD and may greatly contribute to the information processing for sound localization. Since this interaural latency difference is due to the IPD, it is not included in the following discussion about the ITD.

Interaural time difference (ITD). In man, the just-detectable ITD is at best $5 \mu \mathrm{sec}$ ( $9 \mu \mathrm{sec}$ on the average) at a $75 \%$ correct point for a noise with a band width of $0 \cdot 15-$ I $7 \mathrm{kHz}$ and 60-80 dB above the sensation level (Klumpp \& Eady, I956). This ITD 
Forresponds to placing a sound source $\mathrm{I} \cdot \mathrm{I}^{\circ}$ lateral from the median plane (Fedderson et al. 1957). Fedderson et al. (1957) calculated the ITD as a function of azimuth for a sphere with a diameter of $17.5 \mathrm{~cm}$, which is equal to the interaural distance in man, and found that the calculated values ( $9 \mu \mathrm{sec} / \mathrm{degree})$ are very similar to the values measured with microphones placed in the ears of human subjects. In Myotis grisescens and $M$. lucifugus, the interaural distance is ca. $9 \mathrm{~mm}$. The ITD for Myotis as a function of azimuth angle can be obtained by multiplying the ITD for man by the ratio between the interaural distances, 0.05 . The calculated ITD curve showed a slope of about $0.45 \mu \mathrm{sec} /$ degree from the median plane to $40^{\circ}$ lateral. If one assumes that the just-detectable ITD in Myotis is $5 \mu \mathrm{sec}$ as in some human subjects, the theoretical limit for the just-detectable azimuth difference would be $11^{\circ}$. In order to detect a $0 \cdot 7-1 \cdot 7^{\circ}$ azimuth difference with the ITD cue, the just-detectable ITD should be at least $0.3-0.8 \mu \mathrm{sec}$ or less. The just-detectable ITD of Myotis should therefore be assumed to be 8-17 times smaller than that of man, if the ITD cue is to be considered equally important to the IPD cue for echolocation. No data have been obtained yet to indicate whether the above assumption is reasonable or not. According to the above assumption the minimum time-pressure trading ratio is $0.6-\mathrm{I} .6 \mu \mathrm{sec} / \mathrm{dB}$, which is much smaller than the value for man, 9-I I $\mu \mathrm{sec} / \mathrm{dB}$ (Hershkowitz \& Durlach, 1969; Gilliom \& Sorkin, 1972).

In Eptesicus and Phyllostomus the just-detectable azimuth difference is $6-8^{\circ}$ and $4^{-6^{\circ}}$, respectively (Peff \& Simmons, 1971). Since the interaural distance is about $14 \mathrm{~mm}$ for Eptesicus and $22 \mathrm{~mm}$ for Phyllostomus, the ITD at the just-detectable azimuth difference is about $5 \mu \mathrm{sec}$. Thus, the ITD cannot be ruled out as a cue for sound localization, although it is apparently inferior as a cue to the IPD.

Primary auditory neurones of mammals commonly show phase-locked responses to sounds lower than $5 \mathrm{kHz}$ (Rose et al. 1967). In bats, orientation sounds are higher than $10 \mathrm{kHz}$, so that phase-locked responses may not play any role in echolocation. Since the orientation sound of Myotis is always frequency-modulated by about one octave, the ITD is coded by many neurones tuned at different frequencies within the sound. If the ITD plays an important role in echolocation, FM sounds are much better signals than $\mathrm{CF}$ sounds or noise bursts.

\section{SUMMARY}

I. Radiation patterns of the 55,75 and $95 \mathrm{kHz}$ components in frequency-modulated sounds emitted by the grey bat (Myotis grisescens) were studied. FM sounds similar to species-specific orientation sounds were elicited by electrical stimuli applied to the midbrain while the head of the animal was immobilized by a nail cemented to its skull. The main beam was emitted $5^{-10^{\circ}}$ downward from the eye-nostril line. The radiation angle at one half of maximum amplitude was $38^{\circ}$ lateral, $18^{\circ}$ up and $50^{\circ}$ down at $55 \mathrm{kHz}, 34^{\circ}$ lateral, $8^{\circ}$ up and $32^{\circ}$ down at $75 \mathrm{kHz}$, and $30^{\circ}$ lateral, $5^{\circ}$ up and $25^{\circ}$ down at $95 \mathrm{kHz}$. At $95 \mathrm{kHz}$, two prominent side lobes were present.

2. The directional sensitivity of the auditory system (DSA) measured in terms of the potential evoked in the lateral lemniscus was studied with the grey bat $(M$. grisescens) and the little brown bat ( $M$. lucifugus). The maximally sensitive direction moved toward the median plane with the increase in frequency from $35-95 \mathrm{kHz}$. The slope of the DSA curve increased from $0.3-0.6 \mathrm{~dB} /$ degree with frequency. 
3. The directional sensitivity of the echolocation system (DSE) was calculate using both the DSA curve and the radiation pattern of the emitted sound. The maximally sensitive direction of the echolocation system was $15^{\circ}$ lateral to the median plane at $55 \mathrm{kHz}$ and $2.5^{\circ}$ lateral at $95 \mathrm{kHz}$. The slope of the DSE curve increased from 0.6 to $1.0 \mathrm{~dB} /$ degree with frequency. Thus, the higher the frequency of sound, the sharper was the directional sensitivity of the echolocation system.

4. The interaural pressure difference (IPD), which appeared to be the essential cue for echolocation in Myotis, changed linearly with the azimuth angle from o- $30^{\circ}$ lateral regardless of the frequency of sound, at respective rates of $0.4,0.7,0.3$ and $0.4 \mathrm{~dB} /$ degree for $35,55,75$ and $95 \mathrm{kHz}$ sounds. Beyond $30^{\circ}$, the change in IPD was quite different depending on frequency. For 75 and $95 \mathrm{kHz}$ sounds, the IPD stayed nearly the same between $30^{\circ}$ and $90^{\circ}$. Thus, the $75-95 \mathrm{kHz}$ components in FM orientation sounds were not superior to the 35 and $55 \mathrm{kHz}$ components in terms of the IPD cue for echolocation.

5. Assuming the just-detectable IPD and ITD to be $0.5 \mathrm{~dB}$ and $5 \mu \mathrm{sec}$ respectively, as in man, the just-detectable azimuth difference of Myotis around the median plane would be $0.7^{-1} 7^{\circ}$ with the IPD cue and $I I^{\circ}$ with the ITD cue.

These experiments were supported by the National Science Foundation (Research Grant GB-I 3904-AI). We wish to thank Dr J. Simmons for his valuable discussion and $\mathrm{Mr} \mathrm{T}$. Gass for his assistance. We also thank Drs G. Neuweiler and H.-U. Schnitzler for permitting us to reproduce their data.

\section{REF EREN CES}

Fedpereson, W. E., SANDel, T. T., Ters, D. C. \& JefFres, L. A. (1957). Localization of high-frequency tones. Э. acoust. Sac. Am. 29, 988-9r.

Gilliom, J. D. \& Sorkin, R. D. (1972). Discrimination of interaural time and intensity. Y. acoust. Soc. Am. 52, $1635-44$.

GrIfFIN, D. R. (1958). Listening in the Dark. New Haven, Conn. U.S.A.: Yale University Press.

Griffin, D. R., Webster, F. A. \& Michat, C. R. (1960). The echolocation of flying insects by bats. Anim. Behav. 8, 141-54.

GrINNELL, A. D. ( 1963 ). The neurophysiology of audition in bats : directional localization and binaural interaction. F. Physiol., Lond. 167, 97-113.

Grinnel,L, A. D. \& GrinNell, V. S. (1965). Neural correlates of vertical localization by echo-locating bats. F. Physiol., Lond. 181, 830-51.

Harrison, J. M. \& DownEY, P. (1970). Intensity changes at the ear as a function of the azimuth of a tone source: a comparative study. F. acoust. Soc. Am. 47, 1509-i 8.

Hershkowitz, R. M. \& DurLach, N. I. (1 969). Interaural time and amplitude jnds for a $500 \mathrm{~Hz}$ tone. J. acoust. Soc. Am. 46, 1464-7.

KLUMPP, R. G. \& EADY, H. R. (1956). Some measurements of interaural time difference thresholds. Y. acoust. Soc. Am. 28, 859-60.

Milıs, A. W. (1958). On the minimum audible angle. $\mathcal{F}$. acoust. Sac. Am. 30, $237-46$.

Mills, A. W. (1960). Lateralization of high-frequency tones. F. acoust. Soc. Am. 32, I 32-4.

Morres, F. P. (1966). Ultrasonic orientation in Megadermatid bats. In Animal Sonar Systems (ed. R.-G. Busnell), pp. I I 5-27. France: Jouy-en-Josas.

NeUWEILER, G. (1970). Neurophysiologische Untersuchungen zum Echoortungssystem der Grossen Hufeisennase Rhinolophus ferrum equinum Schreber, 1 774. Z. vergl. Physiol. 67, 273-306.

Nordlund, B. \& Fritzell, P. J. (1963). The influence of azimuth on speech signals. Acta oto-lar. 56, $632-42$.

PaYNe, R. (1961). Acoustic orientation of prey by the barn owl, Tito alba. Div. Eng. Applied Physics, Harvard Univ., Cambridge, Mass., U.S.A. Tech. Rep. I.

Peff, T. C. \& Simmons, J. A. (1971). Horizontal-angle resolution by echolocating bats. F. acoust. Soc. Am. 51, 2063-5.

Pumphrey, R. R. (1948). The sense organs of birds. Ibis 90, $171-99$. 
ose, J. E., Brugge, J. F., Anderson, D. J. \& Hind, J. E. (I967). Phase-locked response to lowfrequency tones in single auditory nerve fibers of the squirrel monkey. $Y$. Neurophysiol. 30, 769-93.

SCHNITZLER, H.-U. (I g68). Die Ultraschall-Ortungslaute der Hufeisen-Fledermause (ChiropteraRhinolophidae) in verschiedenen Orientierungasituationen. $Z$. vergl. Physiol. 57, 376-408.

Simmons, J. A. (1969). Acoustic radiation patterns for the echolocation bats Chilonycteris rubiginosa and Eptesicus fuscus. Y. acoust. Soc. Am. 46, 1054-6.

Sivian, L. J. \& White, S. D. (1933). Minimum audible sound fields. F. acoust. Soc. Am. 4, 288-321. Smith, J. D. (1972). Systematics of the chiropteran family Mormoopidea. Museum of Natural History, Univ. Kansas, Lawolence, Kansas, U.S.A. no. 56.

SoKolov, B. V. \& MAKAROV, A. K. (197I). The direction of ultrasonic orientation radiation of the large Rhinolophida and the role of nasal outgrowths in its formation. Sci. Rep. of the Higher School, Biol. Sci. No. 7 Physiol. and Biochem. of Animals 37-44 (in Russian).

Stevins, S. S. \& Newman, E. B. (1936). The localization of actual sources of sound. Am. F. Prychol. 48, 297-306.

Strother, G. K. \& Mogus, M. (1970). Acoustical beam patterns for bats: some theoretical considerations. F. acoust. Soc. Am. 48, 1430-2.

SugA, N. (1964). Single unit activity in cochlear nucleus and inferior colliculus of echo-locating bats. F. Physiol., Lond. 172, 449-74.

SUGA, N. (1971). Responses of inferior collicular neurones of bats to tone bursts with different rise times. Y. Physiol., Lond. $217,159-77$.

SugA, N. \& Schlbarl, P. (1972). Neural attenuation of responses to emitted sounds in echolocating bats. Science, Washington D.C., U.S.A. 177, 82-4. 
